\title{
Translation of Six Tuple Grade-1 Braille Alphabet to English Alphabet
}

\author{
Vishwanath Venkatesh Murthy, M Hanumanthappa
}

\begin{abstract}
Braille is the language used by visually impaired persons. Braille language comprises of collection of Braille cells which are embossed on a metal plate. Maintaining these bulky metal plates and distributing them to other parts of the world is a challenging task. This paper proposes a new technique of translating the Braille Cells embossed on plate to a natural language English character which can be easily distributed over network to make it globally accessible. Initially Braille documents are scanned, and preprocessing techniques like adaptive histogram and Laplacian filters are applied to augment the dots by eliminating the noise. The existence of dot pattern in every cell is detected with a Threshold and transformed to sequence of Binary matrix. A cell information is translated to $3 \times 2$ matrix with binary values of 0 's and 1 's representing absence and presence of dots in a cell. Convolutional Neural Network is used for feature extraction and Classification and Regression Trees (CART) classifier is utilized for recognize the character.

Keywords: Adaptive histogram, Braille, CART, CNN, CNART, Dilation, erosion, grade-1, segmentation, Threshold.
\end{abstract}

\section{INTRODUCTION}

$\mathrm{B}_{\text {raille system used by blind people consists of raised }}$ or embossed dots on metal plate assembled in the form of cells. One single cell can represent total 64 various combinations of embossed dots. Each Braille cell is embossed by any of the combination of one to six dots, whereas the count and place of the embossed dots contained by a cell communicates to the user about the digit, letter, word, or symbol which is symbolized by that cell. As and when the abbreviations and contractions were developed due to the needs of users, Braille system now consists of three versions of grades, namely grade- 1 braille for one-to-one mapping, grade-2 braille for shortened-word mapping and grade-3 Braille for personalized convenience [2].

\section{- Grade-1 Braille}

The Grade- 1 system of braille, the arrangement of dots within a cell maps letter-by-letter replacement for alphabets, digits, or punctuations. The representation of entire words or abbreviations is not allowed in the grade- 1 of Braille.

Manuscript received on June 23, 2021.

Revised Manuscript received on July 13, 2021.

Manuscript published on July 30, 2021.

* Correspondence Author

Vishwanath Venkatesh Murthy*, Assistant Professor, RNS Institute of Technology, Research scholar, Department of Computer Science and Applications, Bangalore University, Bengaluru, India. Email: vm.rnsit@gmail.com

M Hanumanthappa, Department of Computer Science and Applications, Bangalore University, Bengaluru, India. Email: anu6572@hotmail.com

(C) The Authors. Published by Blue Eyes Intelligence Engineering and Sciences Publication (BEIESP). This is an open access article under the CC BY-NC-ND license (http://creativecommons.org/licenses/by-nc-nd/4.0/)
Because the Grade-1 does not support for word and abbreviations, producing books, documents or journals in grade-1 results in bulky and huge quantity of braille plates compared to grade- 2 or printed text.

\section{- Mapping of 6 tuple braille cell to English alphabet}

The word Braille is originated indirectly from the Latin alphabet. According to French alphabet and its position within the alphabetic order; the dot patterns within cell were designated to letters with emphasized alphabets and ' $w$ ' being sorted at the end [4]. The dot patterns of Braille are mapped using the logic as shown in the table-1.

Table-1: Dots pattern mapping with various characters

\begin{tabular}{|c|c|c|}
\hline $\begin{array}{l}\text { The initial (three } \\
\text { alphabets and } \\
\text { digits), } \\
(\mathrm{a}, \mathrm{b}, \mathrm{c})=(1,2,3)\end{array}$ & {$\left[{ }^{\bullet}\right]\left[{ }^{*}\right]\left[{ }^{* *}\right]$} & $\begin{array}{l}\text { Dots from First row } \\
\text { and first column } \\
\text { except ' } a \text { ' }\end{array}$ \\
\hline three vowels (aei) & {$\left[{ }^{\circ}\right]\left[\bullet^{\bullet}\right]\left[\bullet^{\bullet}\right]$} & Dots from diagonal. \\
\hline $\begin{array}{l}\text { Even } \\
\text { characters } \\
(d, f, h, j)=(4,6, \\
8,0)\end{array}$ & $\begin{array}{l}{[\because[][\because][\because *]} \\
{[\because]}\end{array}$ & $\begin{array}{l}\text { right angles on } \\
\text { conners. }\end{array}$ \\
\hline
\end{tabular}

The upper 4 dot patterns represent the initial alphabet range (a to $\mathrm{j}$ ) or numbers range (1-9 and 0 ) are exhibited in the table-2.

Table-2: Initial 10 alphabets of Grade-1 Braille Characters.

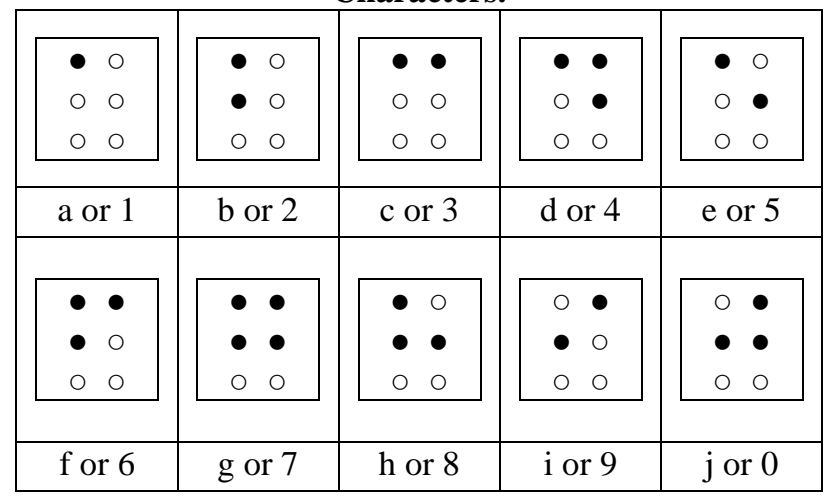

The next range ( $\mathrm{k}$ to $\mathrm{t}$ ) of ten alphabets are similar mapped to the alphabet range (a to j); with addition of one more dot position in last row. The remaining part of the alphabet range ( $\mathrm{u}$ to $\mathrm{v}$ and $\mathrm{x}$ to $\mathrm{z}$ except letter $\mathrm{w}$ ) has been added with one more dot position is shown in table-3. for letter ' $w$ ', the dot is added only at position 2 of last row instead of $1^{\text {st }}$ position [10].
Blue Eyes Intelligence Engineering and Sciences Publication 
Table-3: Alphabets mapping of (k to w) with respect to Grade-1 Braille.

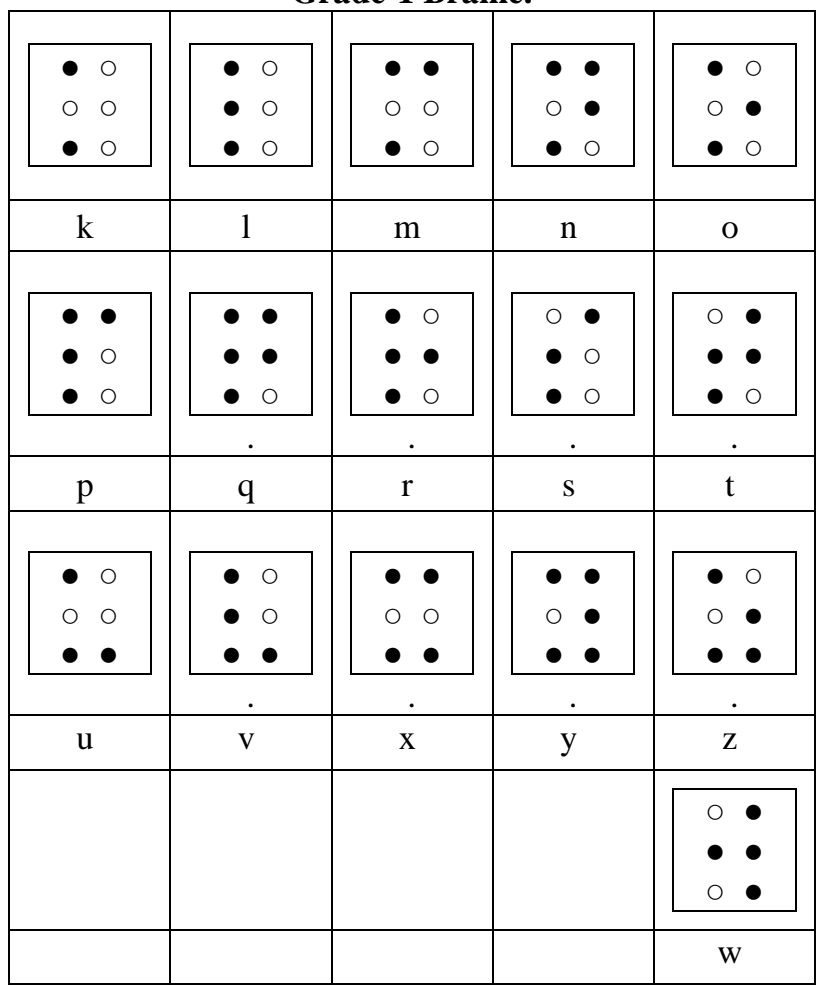

Now basic question is how to differentiate between alphabet or a number. The English braille uses various formatting patterns as shown in table-4.

Table-4: Grade-1 format patterns to identify number and Capital letters.

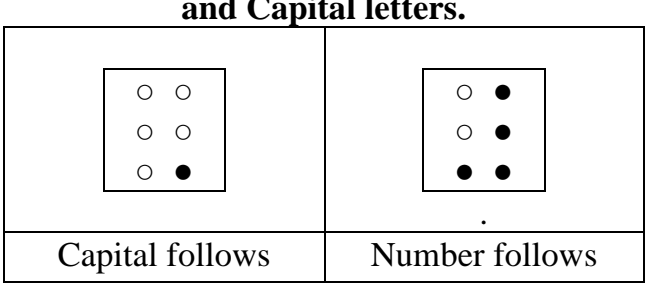

The braille cell. symbolizes that the cell follows this. will all be a capital character and rest all will again be the small letters. Hence using capital sign of table-4, the

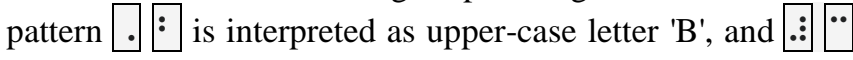
is interpreted as the number '2', similarly the format pattern $. \cdot \because: \because: \because$ is interpreted as capital 'Ant', where only first word is capital, and $\bullet: \because::$ is interpreted as small case 'ant'.

To make the whole word as capitalized, two capital signs are used. Hence the pattern $.0 .0 \cdot \because::$ is interpreted as whole word capital 'ANT'. The punctuation marks required in English Braille uses the format pattern as shown in the table-5. Total 12 punctuation marks that are represented using various Braille patterns.
Table-5: Grade-1 Braille Character pattern to represent punctuation marks.

\begin{tabular}{|c|c|c|}
\hline $\begin{array}{ll}0 & 0 \\
- & 0 \\
0 & 0\end{array}$ & $\begin{array}{ll}0 & 0 \\
- & 0 \\
- & 0 \\
\end{array}$ & $\begin{array}{ll}0 & 0 \\
0 & 0 \\
0 & 0\end{array}$ \\
\hline Comma (,) & Semicolon (;) & Apostrophe (') \\
\hline $\mid \begin{array}{ll}0 & 0 \\
\bullet & \bullet \\
0 & \bullet\end{array}$ & $\begin{array}{ll}0 & 0 \\
- & \bullet \\
- & 0\end{array}$ & $\begin{array}{ll}0 & 0 \\
- & 0 \\
- & 0\end{array}$ \\
\hline Full stop(.) & Exclamation(!) & $\begin{array}{c}\text { question mark (?) / open } \\
\text { quote (“) }\end{array}$ \\
\hline $\begin{array}{ll}0 & 0 \\
- & 0 \\
0 & 0\end{array}$ & $\begin{array}{ll}0 & 0 \\
0 & 0 \\
- & \bullet\end{array}$ & $\begin{array}{ll}0 & \bullet \\
0 & 0 \\
0 & \bullet\end{array}$ \\
\hline Colon (:) & Hyphen (-) & Decimal point (.) \\
\hline $\begin{array}{ll}0 & 0 \\
0 & \bullet \\
\bullet & \bullet\end{array}$ & $\begin{array}{ll}0 & 0 \\
- & \bullet \\
- & \bullet\end{array}$ & $\begin{array}{ll}0 & \bullet \\
0 & 0 \\
- & 0 \\
\end{array}$ \\
\hline $\begin{array}{l}\text { Closing } \\
\text { quote (") }\end{array}$ & Parenthesis ( $\{$ ) & Slash (/) \\
\hline
\end{tabular}

As an example, the sentence "I, like him!" can be

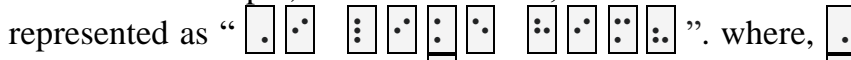
represents "Capital follows", $-\bullet$ represents "comma" and :. represents "Exclamation point".

\section{RELATED WORK}

Proposed method proceeds with color image of Braille document as an input. Initially contrast Enhancements is used with low and high contrast along with Normal and Adaptive Histogram Equalization which converts every pixel using a transformation function that is obtained from the neighborhood region. Threshold helps in identifying the existence of the dots in every cell boundary and it is converted to a matrix of 3x2 order with 0's and 1's for each dot. Convolutional Neural Network has been used for feature extraction and "Classification And Regression Trees" (CART) classifier is utilized for recognize the character [13].

The steps of proposed method are shown in figure1. The various steps of proposed implementation are shown in figue-1.

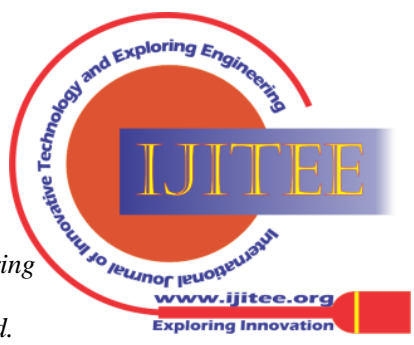




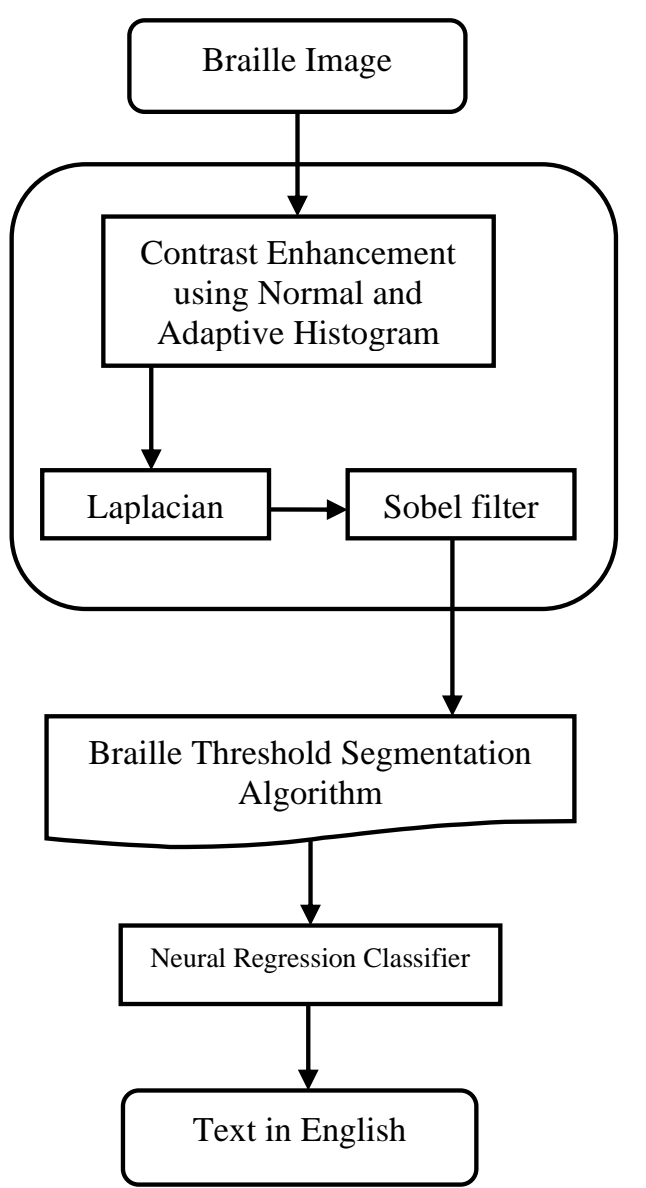

Figure-1: Proposed implementation method

The algorithm for translating the Braille cell to character is shown below:

- $\quad$ Input the color image taken from Kaggle website or the Braille image input by user [2].

- Preprocess the image using Adaptive histogram and Laplacian filter.

- Apply Segmentation to extract braille cell using Neural Regression Classifier.

- Feature extraction is performed using Convolutional Neural Network.

- The Classification and Regression Trees (CART) classifier is used for recognizing the character.

In the first stage if the image is taken from Kaggle website we need not apply preprocessing. But if the image is user input, we need to convert the color image to grayscale. In a grayscale image, the color shades are replaced simply by gray shades. Grayscale image needs less information for representing each pixel. The MATLAB function rgb2gray $(R G B)$ converts color image into grayscale image. This function eliminates the hue and saturation of RGB color image but retains the luminance while converting to grayscale. It forms the weighted sum of $R, G$ and $B$ components as illustrated in the equation-1.

$$
0.2989 * \mathrm{R}+0.5870 * \mathrm{G}+0.1140 * \mathrm{~B}---(1)
$$

In the stage2 of algorithm, Adaptive method calculates many histograms based on diverse sectors of an image which helps in contrast enhancement of the image. It improves the local contrast and augment the edges of each region in an image. The Adaptive histogram consists of three modes. The Mode1 of histogram characterizes the dark section of a recto and verso dot [1]. The Mode2 signifies the background while Mode3 signifies the pale region of a recto as well as verso dot. To enhance the Dots, the Laplacian filter is used for preprocessing to remove the noise from images. Edge detectors like Laplacian filter will help recognize the cell boundaries. The resultant preprocessed image is shown in figure-2b.

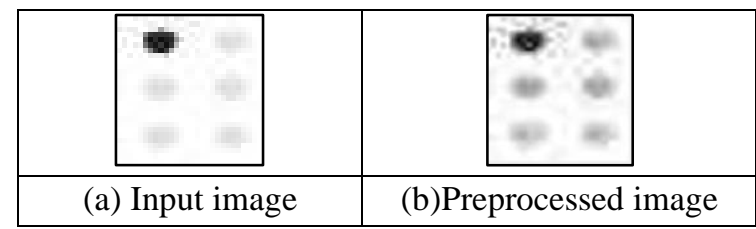

Figure-2: Input image and the image after preprocessing

The dots pattern of each cell is recognized with the help of Threshold. After recognizing, pattern is mapped with Binary digit pattern. The Binary pattern further converted to the respective character of local language. The binary sequence helps in identifying the existence of dot by taking count of number of pixels of white region mapping each cell-grid that satisfies the required criteria for given threshold. Binary 'digit-1' tells the presence of dot while the 'digit- 0 ' tells the absence of dot of the mapped cell region.

To translate the image into text, it was first converted into a grid of 1's and 0 's, 1 being a black dot, and 0 being the absence of one. Knowing where the black dots are is the easy part. But to figure out the locations of the missing dots we had to calculate some distances. The official US standard for braille is shown in the figure-3a.

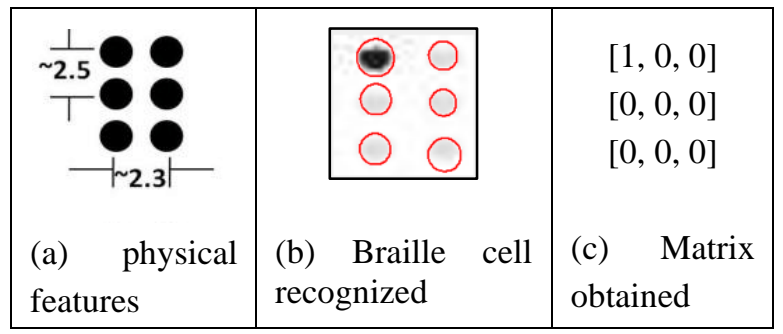

Figure-3: US standard physical features of Braille and resultant matrix obtained.

To make creating the grid easier, all the dots are aligned in one line that have the same y-coordinate, and all dots in one column to have the same $\mathrm{x}$-coordinate. An array of coordinates is created for vertical lines that roughly separate columns of dots, the grid can now be filled in. if the entire line of letters is missing from the bottom row (none of the letters in a row have black dots in positions 5 or 6 ) then add a row of 0 's so the dots from the rows below don't accidentally become part of letters above them. Similarly, if every first letter on each line is missing dots in the first column (positions 1, 3, 5), we need to make sure to account for the fact that our dot array will be starting from the middle of a letter and combine pairs of columns accordingly. Resultant matrix is shown in the figure-3c.

Published By:

Blue Eyes Intelligence Engineering and Sciences Publication

(C) Copyright: All rights reserved.

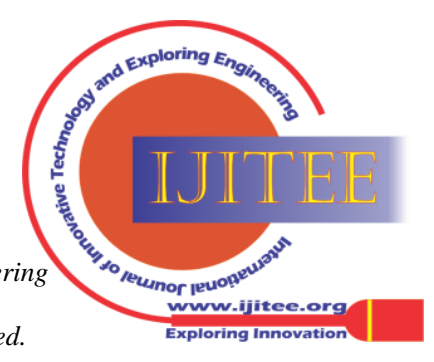


This bit-string of the mapping Braille alphabets is stored to a file. Further using threshold segmentation algorithm, a cell information is translated to 3x2 matrix with binary data of 0 's and 1's symbolizing about absence and presence of dots in a cell. Neural Regression Classifier can be applied to recognize the mapped cells with natural language character like English.

Further, Hybrid Classifier as Neural Regression Classifier is used. Hybrid Classifier as CNART is used. It consists of CNN and Classification and Regression Trees classifier algorithm. Here, Convolutional Neural Network is used for feature extraction and Classification and Regression Trees (CART) classifier is utilized for recognize the character.

\section{RESULTS AND CONCLUSION}

Braille character Dataset is referred from the "Kaggle" website, which is freely available [2]. To assess the effectiveness of the Braille system, the physical list of Braille characters is compared with the obtained results the said system. The results of accuracy parameter of correctly recognized alphabets after mapping are shown in table-6.

Table-6: Results obtained for Grade-1 Braille.

\begin{tabular}{|l|l|l|l|}
\hline $\begin{array}{l}\text { Braille } \\
\text { category }\end{array}$ & $\begin{array}{l}\text { No of } \\
\text { Braille } \\
\text { cells }\end{array}$ & $\begin{array}{l}\text { Correctly } \\
\text { recognized }\end{array}$ & $\begin{array}{l}\text { Accuracy } \\
\%\end{array}$ \\
\hline $\begin{array}{l}\text { Alphabets } \\
\text { capital }+ \\
\text { small case) }\end{array}$ & 52 & 51 & $100 \%$ \\
\hline $\begin{array}{l}\text { Punctuation } \\
\text { marks }\end{array}$ & 12 & 12 & $100 \%$ \\
\hline Numbers & 10 & 10 & $100 \%$ \\
\hline
\end{tabular}

This paper focuses on the conversion of scanned Braille documents are used in this paper that focus on converting them to text in English language. After the preprocessing, subsequently the Braille cell pattern is segmented. Grid matrix is drawn using the physical positional properties of the Braille cell. Every cell in Braille has its own standard configuration which are mapped and identified as alphabet. The recognition of dot will be affected if standard measurement is not reflected in the original input document, which may be due to noise introduced during scanning. The paper could be extended for Grade 2 English documents for recognition of word as well as entire document at once.

\section{REFERENCES}

1. AbdulMalik S. Al-Salman, Ali El-Zaart, Yousef Al-Suhaibani, Khaled Al-Hokail, AbdulAziz O. Al-Qabbany. "An Efficient Braille Cells Recognition" , 2010 International Conference on Computational Intelligence and Software Engineering, 2010

2. https://www.kaggle.com/shanks0465/braille-character-dataset

3. B. S. Nagesh and N. P. Kavya, "Polyp Detection in Endoscopy videos using cascaded classification," 2021 Third International Conference on Intelligent Communication Technologies and Virtual Mobile Networks (ICICV), 2021, pp. 553-557, doi: 10.1109/ICICV50876.2021.9388443.

4. I. G. Ovodov, "Semantic-based Annotation Enhancement Algorithm for Semi-supervised Machine Learning Efficiency Improvement Applied to Optical Braille Recognition," 2021 IEEE Conference of
Russian Young Researchers in Electrical and Electronic Engineering (ElConRus), 2021, pp. 2190-2194, doi: 10.1109/ElConRus51938.2021.9396534.

5. J. Mao, J. Zhu, X. Wang, H. Liu and Y. Qian, "Speech Synthesis of Chinese Braille with Limited Training Data," 2021 IEEE International Conference on Multimedia and Expo (ICME), 2021, pp. 1-6, doi: 10.1109/ICME51207.2021.9428160.

6. Kawabe H., Seto S., Nambo H., Shimomura Y. (2020) Experimental Study on Scanning of Degraded Braille Books for Recognition of Dots by Machine Learning. In: Xu J., Ahmed S., Cooke F., Duca G. (eds) Proceedings of the Thirteenth International Conference on Management Science and Engineering Management. ICMSEM 2019. Advances in Intelligent Systems and Computing, vol 1001. Springer, Cham. https://doi.org/10.1007/978-3-030-21248-3_24

7. Li R., Liu H., Wang X., Qian Y. (2019) Effective Optical Braille Recognition Based on Two-Stage Learning for Double-Sided Braille Image. In: Nayak A., Sharma A. (eds) PRICAI 2019: Trends in Artificial Intelligence. PRICAI 2019. Lecture Notes in Computer Science, vol 11672. Springer, Cham. https://doi.org/10.1007/978-3030-29894-4_12

8. P. Kaur, S. Ramu, S. Panchakshari and N. Krupa, "Conversion of Hindi Braille to Speech using Image and Speech Processing," 2020 IEEE 7th Uttar Pradesh Section International Conference on Electrical, Electronics and Computer Engineering (UPCON), 2020, pp. 1-6, doi: 10.1109/UPCON50219.2020.9376566.

9. Park HS., Lee YH., Chun SH., Kim JB. (2020) Implementation of Electronic Braille Document for Improved Web Accessibility. In: Lee R. (eds) Computational Science/Intelligence and Applied Informatics. CSII 2019. Studies in Computational Intelligence, vol 848. Springer, Cham. https://doi.org/10.1007/978-3-030-25225-0_2

10. Sota Sugimura, Kiyoshi Hoshino. "A wearable hand pose estimation with reference data selected according to individual differences in hand shape" , 2016 IEEE International Symposium on Robotics and Intelligent Sensors (IRIS), 2016

11. S. Ramachandran, N. Rajan, K. N. Pallavi, J. Subashree, S. Suchithra and B. Sonal, "Communication Device for the Visual and Hearing Impaired Persons to Convert Braille Characters to English Text," 2021 International Conference on Emerging Smart Computing and Informatics (ESCI), 2021, pp. 587-592, doi: 10.1109/ESCI50559.2021.9396859.

12. Thandapral J.J., Mugelan R.K. (2021) Wearable Tactile Braille Device Using (Modular Low-Cost Braille Electronic Display) MOLBED and Finger-Held Scroller. In: Komanapalli V.L.N., Sivakumaran N., Hampannavar S. (eds) Advances in Automation, Signal Processing, Instrumentation, and Control. Lecture Notes in Electrical Engineering, vol 700. Springer, Singapore. https://doi.org/10.1007/978-981-15-8221-9_56

13. https://wiki.q-researchsoftware.com/wiki/ Machine_Learning_Classification_And_Regression_Trees_(CART)\#.html

\section{AUTHORS PROFILE}

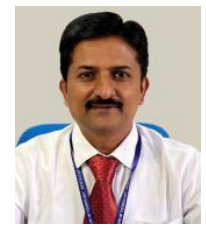

Vishwanath Venkatesh Murthy, has received B.E degree in 1997 and MSc degree in 2004. Currently working as HoD, MCA Department, RNSIT, Bangalore, India. He is pursuing his research as a research scholar in Bangalore University, Bangalore, India. His research area is Data mining \& Image processing.

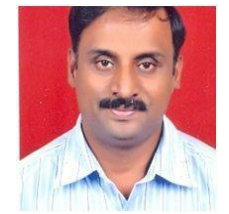

Dr. Hanumanthappa M, Professor and Chairman, Department of Computer Science \& Applications, Bangalore University, Bangalore. His Research Interests are Data Mining, Machine Learning, Network Security, NLP 